DOUBLE STARS IN THE ASTROGRAPHIC CATALOGUE

\author{
CHARLES E. WORLEY \\ U.S. NAVAL OBSERVATORY \\ WASHINGTON, D.C. 20392 U.S.A.
}

\begin{abstract}
Nearly 20000 double stars have been detected from star positions listed in the Astrographic Catalogue. However, an examination of the various discoverer's efforts reveals that the past searches have been very incomplete. In fact, if the limits adopted by one discoverer were applied to the remainder of the catalogue, approximately $3 \cdot 10^{5}$ additional pairs would be found. Is such an endeavor justifiable scientifically?
\end{abstract}

One of the by-products of the creation of the Astrographic Catalogue has been the detection of nearly 20000 double stars, partly from the plates themselves, and partly from the later measures included in the Astrographic Catalogue. Searches were both spotty and incomplete; some zones were never investigated. Moreover, there was a complete lack of uniformity regarding separation and magnitude limits, and the result is that many thousands of demonstrably physical pairs remain undetected. This contribution, therefore, is an attempt to assess the present situation with regard to the double star content of the Astrographic Catalogue.

Table 1 lists the various zones of the Astrographic Catalogue, together with comments regarding the double star searches known to have been conducted in each zone.

TABLE 1.

Searches of The Astrographic Catalogue For Double Stars

Zone

Greenwich
Discoverer

H. Groot
Comment

Among 178784 stars, 2953 pairs found with separations $\leq 30$ ". This work was never published. 


\begin{tabular}{|c|c|c|c|}
\hline Vatican & $+64^{\circ}$ to $+55^{\circ}$ & J. Stein & $\begin{array}{l}3091 \text { numbered pairs, } \\
\text { separations } \leq 15 ", \\
\text { no magnitude limit. }\end{array}$ \\
\hline Catania & +54 to +47 & & $\begin{array}{l}\text { Largely unsearched, } \\
\text { although a few pairs } \\
\text { were noted by } \\
\text { Bemporad between } 12 \\
\text { and } 19 \text { hrs. of R.A. }\end{array}$ \\
\hline Helsingfors & +46 to +40 & & Unsearched. \\
\hline Hyderabad & +39 to +36 & A. Ali & $\begin{array}{l}1192 \text { numbered pairs, } \\
\text { of which only } \\
557 \text { proved new. } \\
\text { Separations } \leq 15 " \\
\text { no magnitude limit. }\end{array}$ \\
\hline Oxford $x$ & +35 to +25 & J.Scheiner & $\begin{array}{l}1562 \text { numbered pairs, } \\
\text { of which only } 1338 \\
\text { are new. Only objects } \\
\text { brighter than } \\
\text { photographic magnitude } \\
\text { 11.1 are listed. } \\
\text { Separations } \leq 30^{\circ} \text {. }\end{array}$ \\
\hline Paris* & +24 to +18 & M.Pourteau & $\begin{array}{l}\text { In the zone }+24^{\circ}, \\
\text { Pourteau listed } \\
5883 \text { pairs with } \\
\text { separations } \leq 20^{\prime \prime} \text {, } \\
\text { magnitudes to } \\
\text { plate limits. }\end{array}$ \\
\hline
\end{tabular}

$\begin{array}{ll}\text { Bordeaux* } & +17 \text { to }+11 \\ \text { Toulouse* } & +11 \text { to }+5\end{array}$

Algiers $+4^{\circ}$ to $-2^{\circ} \quad$ R. Baillaud 3016 pairs, there are 2438 new; some of the new pairs were only suspected, however, and not measured. Separations $\leq 20 "$, faintest magnitudes 11.5 . 


\begin{tabular}{|c|c|c|c|c|}
\hline San Fernando* & $-3^{0}$ to & -90 & & \\
\hline Tacubaya* & -10 to & -16 & J. Gallo & $\begin{array}{l}300 \text { numbered pairs, } \\
\text { but only about } 50 \\
\text { are new. Some very } \\
\text { wide pairs observed } \\
\left(60-80^{\prime \prime}\right) \text {. }\end{array}$ \\
\hline Hyderabad* & -17 to & -23 & S.Aravamudan & $\begin{array}{l}3000 \text { numbered pairs, } \\
\text { of which many are } \\
\text { duplicates. }\end{array}$ \\
\hline Cordoba* & -24 to & -31 & & \\
\hline Perth* & -32 to & -40 & R. Wrigley & $\begin{array}{l}289 \text { numbered pairs } \\
\text { in the zone }-40^{\circ} \text {. } \\
212 \text { are new. Separa- } \\
\text { tions generally }<10^{\prime \prime} \text {, } \\
\text { but about } 108 \text { wider. } \\
\text { Combined magnitudes } \\
\leq 10.8 \text {. }\end{array}$ \\
\hline Cape* & -41 to & -51 & & $\begin{array}{l}\text { Several hundred pairs, } \\
\text { some new. In many } \\
\text { cases only partial } \\
\text { data are listed. }\end{array}$ \\
\hline Sydney* & -52 to & -64 & & $\begin{array}{l}\text { A small number of pairs, } \\
\text { apparently picked out } \\
\text { casually. }\end{array}$ \\
\hline Melbourne* & $-65^{\circ}$ to & $-90^{\circ}$ & & $\begin{array}{l}\text { Small numbers of } \\
\text { stars, with much } \\
\text { missing data. }\end{array}$ \\
\hline
\end{tabular}

Note that zones followed by an asterisk have been searched by S. Barton and his students. These searches, however, were limited in nearly all cases to pairs with separations <5". Thus, large numbers of undetected pairs must still exist in the extensive area of the celestial sphere covered by these searches. Barton also confirmed many of his discoveries through later measures with the Flower Observatory 18-inch refractor, a practice followed by few other discoverers.

A specialized search by P. Gauchet (1926) also utilized the Astrographic Catalogue to identify and provide new measurements for more than a thousand of the rather crudely described double stars found by J. Herschel. 
Thus, the results revealed in Table 1 show that the Carte du Ciel/ Astrographic Catalogue has only been searched very imperfectly for double stars. In general, pairs closer than 5" are increasingly undetectable at the brighter magnitudes as the magnitude difference grows, and the same is of course true for faint stars where the secondary is below the plate limit. Stein (1926) calculated that 48 of the secondaries would also be obscured by the reticle. Also, given that the limiting magnitude varies from plate to plate, and series to series, it becomes very difficult to quantitatively assess the incompleteness of the present searches.

Another problem which must be addressed is: What practical limit of separation should be established in order to assure that most of the detected pairs are physical? Kreiken (1928) pointed out long ago that the number of optical pairs is nearly proportional to the square of the star density: therefore the increase of the number of optical doubles with increasing star density will be much larger than the increase of physical pairs. Thus, for an arbitrary "maximum separation", many more optical pairs will be detected at low galactic latitudes. In his series of contributions on the astrographic double stars, Kreiken goes on to show that most of the pairs detected in the range 15-30" are optical (excepting relatively bright pairs, which, in the main, have already been found by other means). In conclusion, it appears from examination of the data in Table 1 that the adoption of very generous separation limits has resulted in the inclusion in our catalogues of many optical pairs.

Second observations of a new double not only serve to confirm its existence, but often indicate after a period of time the optical or physical nature of the pair. To assess the state of observation of the astrographic doubles, four regions in the WDS (Washington Double Star Catalog) were interrogated, at spacings of six hours of R.A. The results are listed in Table 2 .

Table 2 .

Status of Observation of Astrographic Double Stars

Right Ascension (J2000)

$\begin{array}{lll}00^{\mathrm{h}} & 00^{\mathrm{m}} 0-00^{\mathrm{h}} & 30^{\mathrm{m}} \cdot 0 \\ 06 & 00.0-06 & 30.0 \\ 12 & 00.0-12 & 30.0 \\ 18 & 00.0-18 & 30.0\end{array}$

Number of Pairs

Single Observations

The fact that only $15 \%$ of these pairs have ever been reobserved is in itself instructive: most of the astrographic doubles are faint and wide, and are of little interest astrometrically or astrophysically. 
Pourteau listed nearly 6000 pairs in the +24 degree zone. Were the entire sky to be examined with equal diligence, one can project that more than $3 \cdot 10^{5}$ double stars would result, including a large number of optical pairs. In fact, recent astrographic work by Kazeza (1984) and Soulie (1983-86), which include pairs separated by hundreds of arcseconds, seem to be projects of rather dubious merit, which are only serving to further clutter the double star catalogue with optical pairs. There seems little scientific justification for further work of this sort, unless the pairs can be shown to be of interest through common proper motion or other physical characteristics.

\section{References and Bibliography}

Ali, A.

1955

Aravamudan, S.

1963

Baillaud, R.

1943

Barton, S.

Gallo, J .

1912

1914

Gauchet, P.

1926

Groot, H.

1927

Kazeza, S.

1984

Kreiken, E.

Pourteau, M.

Scheiner, J .

1908

Stein, J.

Soulie, G.

1983

1984

1985

1986

Wrigley, R.
Pub1. Nizamiah Obs. 13, Pt. 2 .

Publ. Nizamiah Obs. 13, Pt. 3 .

Ann. Obs. Besancon, New Ser. 3, 33.

See many volumes of the Astron. J. $36-46,47-48,50,52$, and 55 .

Bol. Tacubaya No. 2 .

Ibid. No. 3.

Ibid. No. 4.

Ann. Shanghai Obs. Zo-Se 14, 131.

Mon. Not. R. Astron. Soc. 88, 51.

Bul1. Astron. R. Obs. Bel. 9, 311.

Bul1. Astron. Inst. Neth. 4; 205, $212,219,228$, and 239.

Obs. de Paris, Cat. des Etoiles Doubles, Zone +24 .

Pub1. Obs. Potsdam 20, Pt. 2.

Vatican Astrographic Catalogue, App. 3, Pts. 1, 2.

Astron. Astrophys. Supp1. 54, 281. Ibid. $56,351$. Ibid. $61,17$. Bull. Inf. Cent. Donnes Stellaires No. 30 .

Mon. Not. R. Astron. Soc. 72, 34. 